\title{
Inhibition of MEK sensitizes gastric cancer cells to TRAIL-induced apoptosis
}

\author{
P. WU' ${ }^{1}$, Y. W. CHENG ${ }^{1}$, J. Y. WANG ${ }^{1}$, X. D. ZHANG ${ }^{2}$, L. J. ZHANG ${ }^{1, *}$
}

${ }^{1}$ Department of Immunology, Anhui Medical University, 230032, 81 Meishan Road, Shushan District, Hefei, Anhui, P. R. China; ${ }^{2}$ School of Medicine and Public Health, University of Newcastle, 2300, New South Wales, Australia

${ }^{*}$ Correspondence: zlj33@ahmu.edu.cn

Received March 14, 2013 / Accepted June 13, 2013

\begin{abstract}
Tumor necrosis factor-related apoptosis-inducing ligand (TRAIL), which has long been believed to be highly selective in inducing apoptosis in cancer cells, has turned out to be a molecule that induces a far more diverse range of effects. The aim of this study was to investigate whether or not ERK1/2 pathway is involved in antitumor effects of TRAIL on gastric cancer cells. In addition to activate the extrinsic and intrinsic apoptotic pathway, TRAIL also triggered the activation of ERK1/2. Inhibition of ERK1/2 signaling by MEK inhibitor U0126 promoted cell death via increased activation of caspases, drop in mitochondrial membrane potential and downregulation of XIAP, cIAP2 and Mcl-1. These results indicate that TRAIL-induced rapid activation of ERK1/2 may be a survival mechanism to struggle against TRAIL assault at the early stage, and inhibition of ERK1/2 signaling can sensitize gastric cancer cells to TRAIL-induced apoptosis.
\end{abstract}

Key words: gastric cancer, TRAIL, ERK1/2, apoptosis

Tumor necrosis factor-related apoptosis-inducing ligand (TRAIL) is a member of the tumor necrosis factor (TNF) family that appears to be a promising candidate for cancer therapeutics because it has the ability to preferentially initiate apoptosis in malignant cells with minimal toxicity to normal cells $[1,2]$. The potential significance of TRAIL has been supported by studies in animal models showing selective toxicity to human tumor xenografts but not normal tissues [3].

Induction of apoptosis by TRAIL is mediated by its interaction with two death receptors, TRAIL-R1 and -R2. This in turn orchestrates the assembly of adaptor components such as Fas-associated death domain (FADD) and pro-caspase-8, leading to the formation of the death-inducing signaling complex (DISC) in which pro-caspase- 8 is activated by dimerization and subsequent autocatalytic cleavage. The activated caspase8 can then activate downstream effector caspases such as caspase-3 either directly (extrinsic pathway) or indirectly by recruitment of the mitochondria (intrinsic pathway), leading eventually to apoptosis. Crosstalk between the extrinsic and intrinsic apoptotic pathways is accomplished by caspase- 8 cleavage of Bid into truncated Bid (tBid). tBid activates Bax and Bak, leading to mitochondrial pore formation through their oligomerization. Subsequently, cytochrome c translocates from mitochondria to cytoplasm where it induces the assembly of apoptosome and activation of caspase-9. In parallel, Smac/ DIABLO leaves intermembrane compartment of mitochondria and releases caspase- 3 and caspase- 9 from Inhibitor of apoptosis proteins (IAPs) -mediated inhibition [2].

Pre-existing or acquired resistance is a common obstacle in cancer therapy. Studies using cell lines, preclinical animal models and clinical trials indicate that TRAIL-based therapeutics are no exception. Theoretically, resistance mechanisms could target any of the events starting from TRAIL ligand- binding through to the end point of apoptosis by affecting the expression and/or function of TRAIL pathway components. Multiple mechanisms have been identified, including downregulation of TRAIL-R1 and/or -R2 [4, 5], elevated cFLIP [6], loss of proapoptotic Bax [7] and/ or Bak [8] as well as overexpression of anti-apoptotic Bcl-2 [9], Bcl-X $\mathrm{L}_{\mathrm{L}}[10]$ and $\mathrm{Mcl}-1[11,12]$ and high expression level of IAPs [13].

In addition to triggering apoptosis, TRAIL also promotes the activation of noncytotoxic signal pathway, including nuclear factor- $\kappa \mathrm{B}(\mathrm{NF}-\kappa \mathrm{B})$ [14], mitogen-activated protein kinases (MAPKs) [15] and protein kinase B (PKB)/Akt [16]. The signaling events downstream of receptor ligation have not been fully clarified, but proteins such as FADD, caspase-8, TNF receptor type 1 -associated death domain (TRADD), receptor-interacting protein (RIP), TNF receptor-associated factor 
2 (TRAF2), NEMO/IKK $\gamma$ and cIAP1/2 appear to be involved in regulating these alternative pathways [15]. So the balance between apoptotic and non-apoptotic pathways seems to have a decisive role in determining the cellular fate.

MAPKs are a group of protein serine/threonine kinases that are activated in response to a variety of extracellular stimuli. In mammalian cells, three major types of MAPKs cascades have been identified: extracellular signal-regulated kinase 1/2 (ERK1/2), Jun N-terminal kinase (JNK) and p38 kinase. In the ERK1/2 pathway, activation of receptor tyrosine kinases by growth factors induces phosphorylation and activation of a cascade of kinases, including Ras, Raf, MAP/ERK kinase (MEK), and ERK. The active phosphorylated form of ERK1/2 (p-ERK) translocates to the nucleus and phosphorylates transcription factors that control cell proliferation and differentiation [17]. Past studies have shown that constitutive activation of MEK/ERK pathway is a common cause for resistance of cells to death receptor-mediated or mitochondria-mediated apoptosis. Recently, blocking MAPK via small-molecule MEK inhibitors has come to the forefront as an exciting approach in cancer therapeutics. MEK inhibitors can potentiate the effect of other anticancer therapeutic agents including TRAIL [18-20].

In the present study, we investigated the role of ERK1/2 pathway in TRAIL signaling. TRAIL induced rapid but relatively transient activation of ERK1/2, this may be a kind of survival mechanism to struggle against TRAIL assault at the early stage, and inhibition of MEK could sensitize gastric cancer cells to TRAIL-induced apoptosis, this appeared to be associated with increased activation of caspases, loss of mitochondrial membrane potential, together with downregulation of XIAP, cIAP2 and Mcl-1.

\section{Materials and methods}

Cell culture. Human gastric cancer cell lines BGC-823 and SGC-7901 were obtained from Type Culture Collection of Chinese Academy of Sciences (Shanghai, China). Cells were cultured in DMEM (Gibco, Grand Island, NY, USA) containing $10 \%$ heat-inactivated fetal bovine serum, L-glutamine, and penicillin/ streptomycin in a humid environment of 5\% $\mathrm{CO}_{2}$ at $37^{\circ} \mathrm{C}$.

Reagents. Recombinant human TRAIL was supplied by Immunex (Seattle, WA, USA). MEK inhibitor (U0126), and Reverse Transcription System were purchased from Promega (Madison, WI, USA). Propidium iodide (PI) was obtained from Sigma-Aldrich (St Louis, MO, USA). JC-1 dye was from Molecular Probes (Eugene, OR, USA). The general caspase inhibitor, Z-Val-Ala-Asp (Ome)- $\mathrm{CH}_{2} \mathrm{~F}$ (z-VAD-fmk), the caspase-8 inhibitor, Z-lle-Glu (Ome)-Thr-Asp (Ome)- $\mathrm{CH}_{2} \mathrm{~F}$ (z-IETD-fmk), and the caspase-9 inhibitor, Z-Leu-Glu (Ome)His-Asp (Ome)- $\mathrm{CH}_{2} \mathrm{~F}$ (z-LEHD-fmk) were purchased from Calbiochem (Merck KgaA, Darmstadt, Germany). Mouse monoclonal antibodies against caspase-3, PARP, pERK1/2, caspase- 8 , caspase-9, Bcl-2 and rabbit polyclonal antibodies against ERK1/2, Mcl-1 were all from Santa Cruz Biotechnology (Santa Cruz, CA, USA). Mouse monoclonal antibodies against Bid and Survivin, rabbit monoclonal antibodies against $\mathrm{XIAP}$ and cIAP2, rabbit polyclonal antibodies against $\mathrm{Bcl}-\mathrm{X}_{\mathrm{L}}$ and cIAP1, were obtained from Cell Signaling Technology (Danvers, MA, USA). Premix Ex Taq ${ }^{\mathrm{TM}}$ were purchased from Takara (Dalian, China).

Measurement of apoptosis. Apoptotic cells were determined by the propidium iodide method. Briefly, cells were seeded at $1 \times 10^{5}$ cells/well in 24 -well plates and allowed to reach exponential growth for $24 \mathrm{~h}$ before treatment. Non-adherent cells were collected, and centrifuged at $200 \times g$. A hypotonic buffer of $0.75 \mathrm{ml}(50 \mathrm{mg} / \mathrm{ml}$ propidium iodide in $0.1 \%$ sodium citrate plus $0.1 \%$ Triton X-100) was added directly to the adherent cells for $20 \mathrm{~min}$ at $37^{\circ} \mathrm{C}$, then gently pipetted off. The tubes were placed in $4^{\circ} \mathrm{C}$ in the dark overnight before flow cytometric analysis using a Becton Dickinson FACSCalibur flow cytometer (Franklin Lakes, NJ, USA). The sub-G1 population was calculated to estimate the apoptotic cell population.

Measurement of mitochondrial membrane potential (MMP). Cells were seeded at $1 \times 10^{5}$ cells/well in 24 -well plates and allowed to reach exponential growth for $24 \mathrm{~h}$ before treatment. Adherent cells and non-adherent cells were collected, then incubated with $10 \mu \mathrm{g} / \mathrm{ml}$ of JC-1 in warm PBS at $37^{\circ} \mathrm{C}$ for $15 \mathrm{~min}$. After washing with PBS, the cells were analyzed using a Becton Dickinson FACSCalibur flow cytometer. Cells with polarized mitochondria are in the upper-right quadrant of the dot plot due to the formation of JC-1 aggregates, cells with depolarized mitochondria are visualized in the lowerright quadrant in the dot plot.

Western blot. Cells were harvested, and gently lysed in lysis buffer for $30 \mathrm{~min}$ on ice before centrifugation at $14,000 \times \mathrm{g}$ at $4^{\circ} \mathrm{C}$ for $30 \mathrm{~min}$. Supernatants were collected and protein concentrations were determined by the BCA assay. A total of $20 \mu \mathrm{g}$ of protein was electrophoresed on SDS-PAGE gels and transferred to nitrocellulose membranes (Amersham Biosciences, Buckinghamshire, UK). Membranes were blocked, incubated with primary antibodies, and subsequently incubated with HRP-conjugated secondary antibodies. Labeled bands were detected by Pierce SuperSignal West Femto Chemiluminescent Substrate (Rockford, IL, USA), and images were captured and the intensity of the bands were quantitated with the Tanon $\mathrm{Au}$ tomatic Digital Gel Imaging System 4500 (Shanghai, China).

Real-time PCR. Total RNA was isolated, and reverse transcription was carried out using AMV transcriptase and Oligo $(\mathrm{dT})_{15}$, and the resulting cDNA products were used as template for real-time PCR assays. It was performed using the Applied Biosystems StepOnePlus Real-Time PCR System (Carlsbad, CA, USA). Mcl-1 forward primer: 5'-GGAAGGCCTGGAGACCTTA-3', reverse primer: 5'-CAACGATTTCACATCGTCTTCGT-3', probe: 5' (FAM)TTGATGTCCAGTTTCCGAAGCATGC CT- (ECLIPSE)3' Analysis of cDNA for GAPDH was included as a control. After incubation at $95^{\circ} \mathrm{C}$ for $5 \mathrm{sec}$, the reaction was carried out for 40 cycles as the following: $95^{\circ} \mathrm{C}$ for $15 \mathrm{sec}$ and $60^{\circ} \mathrm{C}$ for $40 \mathrm{sec}$. 

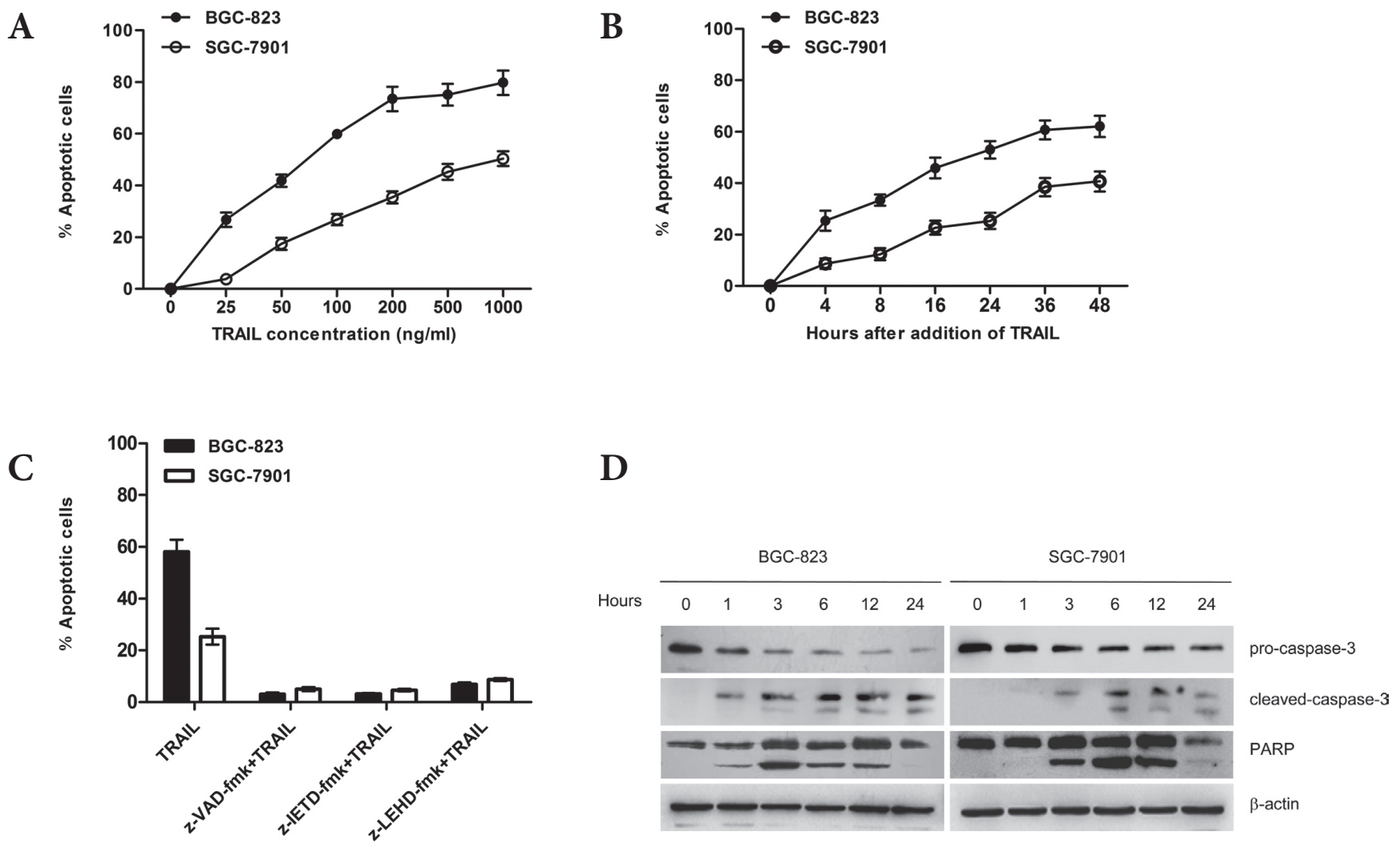

Figure 1. TRAIL induces apoptosis of gastric cancer cells. Cells were treated with (A) increasing concentration of TRAIL for $24 \mathrm{~h}$ or (B) TRAIL (100 ng/ml) for the indicated time or $(\mathrm{C})$ the pan caspase inhibitor $\mathrm{Z}$-VAD-fmk $(20 \mu \mathrm{mol} / \mathrm{L})$, the caspase- 8 inhibitor $\mathrm{Z}$-IETD-fmk $(20 \mu \mathrm{mol} / \mathrm{L})$, or the caspase- $9 \mathrm{inhibitor}$ z-LEHD-fmk $(20 \mu \mathrm{mol} / \mathrm{L})$ for $1 \mathrm{~h}$ before adding TRAIL $(100 \mathrm{ng} / \mathrm{ml})$ for a further $24 \mathrm{~h}$. Apoptosis was analyzed by the propidium iodide method using flow cytometry. Data represent mean \pm SD of three experiments. D, Cells treated with TRAIL $(100 \mathrm{ng} / \mathrm{ml})$ for indicated periods were subjected to Western blot analysis with antibodies against caspase- 3 and PARP. $\beta$-actin was used as loading control.

The threshold cycle value $(\mathrm{Ct})$ was normalized against GAPDH cycle numbers. The relative abundance of mRNA expression of a control sample was designated as 1 , and the values of other samples was calculated accordingly.

Statistical analysis. The experiments were repeated at least three times. Data are expressed as the means \pm SD. Differences in the results for two groups were evaluated by the Student's $t$-test. $P<0.05$ was considered to be statistically significant.

\section{Results}

TRAIL induced apoptosis in gastric cancer cells. We examined the apoptosis-inducing potential of TRAIL by treating the two cell lines with a range of concentrations as follows: 0 , $25,50,100,200,500$ and $1000 \mathrm{ng} / \mathrm{ml}$ for $24 \mathrm{~h}$. As shown in Fig. 1A, TRAIL induced apoptosis of the gastric cancer cells in a dose-dependent manner. Induction of apoptosis by TRAIL at $100 \mathrm{ng} / \mathrm{ml}$ was confirmed by treating the cells for varying time periods (Fig. 1B). Our data showed that the two gastric cancer cell lines were not completely resistant to TRAIL, BGC-823 cells were more sensitive to TRAIL-induced apoptosis than SGC-7901 cells.

To assess the role of caspases in TRAIL-induced apoptosis, cells were pretreated with the pan caspase inhibitor z-VAD-fmk, or specific inhibitors of caspase-8, z-IETD-fmk, or caspase-9, $\mathrm{z}$-LEHD-fmk, $1 \mathrm{~h}$ before adding TRAIL for another $24 \mathrm{~h}$. As shown in Fig. 1C, three inhibitors blocked TRAIL-induced apoptosis nearly completely. Western blot analysis showed that TRAIL-induced rapid caspase- 3 activation and PARP cleavage in gastric cancer cells. In BGC-823 cells, capase-3 activation and PARP cleavage were detected as early as $1 \mathrm{~h}$, while in SGC-7901 cells these were observed at $3 \mathrm{~h}$ (Fig. 1D).

TRAIL induced ERK1/2 activation in gastric cancer cells. To determine the role of ERK1/2 pathway in TRAIL signaling, we investigated ERK activation in the two gastric cancer cell lines. As shown in Fig. 2A, prior to stimulation with TRAIL, the levels of activated (phosphorylated) ERK1/2 were very low, after TRAIL treatment there was strong activation of ERK1/2. In BGC-823 cells, activated ERK1/2 level reached maximum at $30 \mathrm{~min}$ and then downregulated, while, in SGC-7901 cells, it increased at $30 \mathrm{~min}$ and reached a peak at $1 \mathrm{~h}$. 
A

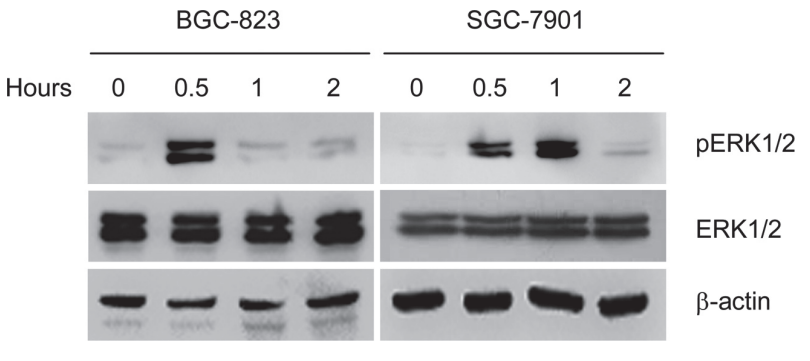

B

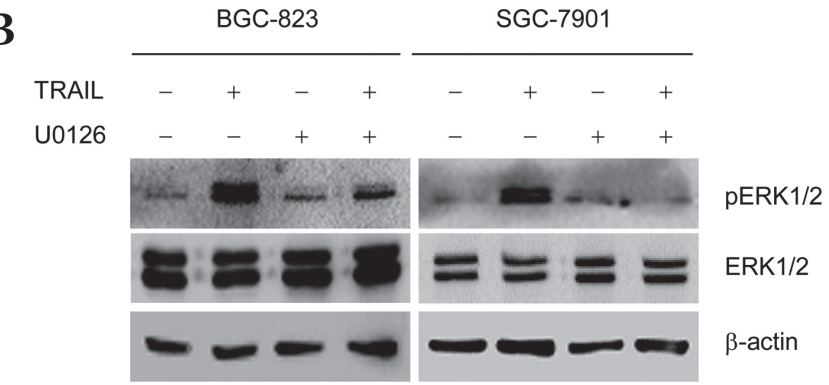

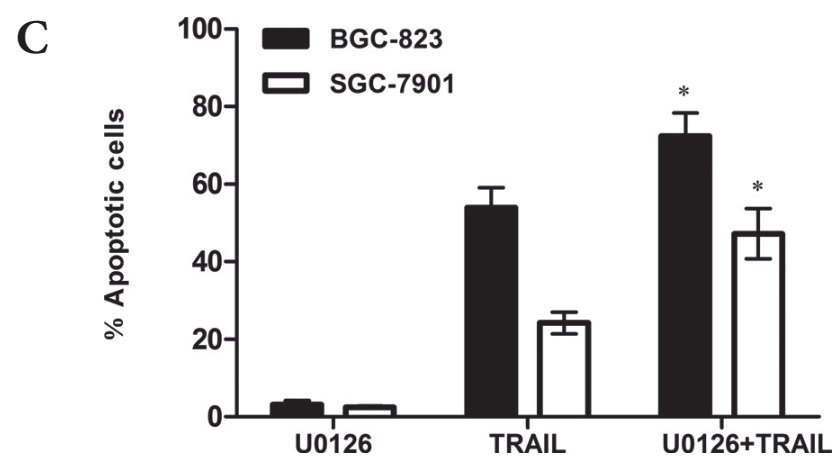

Figure 2. Inhibition of MEK sensitizes gastric cancer cells to TRAIL-induced apoptosis. A, After TRAIL (100 ng/ml) treatment, cells were harvested and cell lysates were subjected to Western blot analysis of pERK1/2 and ERK1/2 expression. B, Cells were incubated with TRAIL (100 ng/ml) for $0.5 \mathrm{~h}$, U0126 $(20 \mu \mathrm{mol} / \mathrm{L})$ for $1 \mathrm{~h}$, or U0126 $(20 \mu \mathrm{mol} / \mathrm{L})$ for $1 \mathrm{~h}$ before adding TRAIL $(100 \mathrm{ng} / \mathrm{ml})$ for another $0.5 \mathrm{~h}$. Identical concentrations were used in later experiments. Whole-cell lysates were subjected to Western blot analysis of pERK1/2 and ERK1/2 expression. C, Cells were treated with TRAIL, U0126, or the combination of U0126 and TRAIL for $20 \mathrm{~h}$ before assay of apoptosis by flow cytometry. Data were represented as mean \pm SD of duplicates. * p $<0.05$ vs TRAIL alone.

Inhibition of ERK1/2 signaling sensitized gastric cancer cells to TRAIL-induced apoptosis. Pretreatment with U0126, a specific MEK inhibitor, followed by exposure to TRAIL effectively attenuated the phosphorylation of ERK1/2 (Fig. 2B). And combined treatment with both TRAIL and U0126 was more effective than TRAIL alone in inducing cell death (Fig. 2C). These results suggested that activation of ERK1/2 pathway may represent a major intracellular mechanism involved in resistance to TRAIL-induced apoptosis of gastric cancer cells.

To explore the molecular mechanisms involved in the sensitization of gastric cancer cells to TRAIL-induced apoptosis by U0126, we studied the key caspases in the extrinsic and intrinsic apoptotic pathway. Exposure to TRAIL alone induced modest cleavage of caspase- 8 and Bid, and there were further increases in caspase- 8 and Bid cleavage in the presence of U0126. Furthermore, the same treatment resulted in a dramatic increase in caspase-9, caspase- 3 activation and PARP cleavage (Fig. 3A). Treatment with U0126 or TRAIL alone resulted in a minor reduction in the $\mathrm{MMP}$, and a considerable drop of MMP was observed when U0126 and TRAIL were combined (Fig. 3B).

Next we examined the involovement of IAPs, as shown in Fig. 3A, TRAIL alone induced a slight decline in the expression of XIAP in the two cell lines, but when U0126 and TRAIL were combined, its expression level reduced sharply. There was also a decrease in the expression of cIAP2 in the SGC-7901 cells, whereas no changes were found in the expression of Survivin and cIAP1 with any treatment in the two cell lines.

U0126 downregulated the levels of Mcl-1 in gastric cancer cells. The intrinsic mitochondrial pathway is regulated by the Bcl-2 family members. After U0126 treatment, Mcl-1 protein level was significantly decreased. In contrast, the expression of $\mathrm{Bcl}-2$ and $\mathrm{Bcl}-\mathrm{X}_{\mathrm{L}}$ remained unchanged (Fig. $3 \mathrm{C}$ ). Consistent with this phenomenon, Mcl-1 mRNA level was downregulated after exposure to U0126 as early as $4 \mathrm{~h}$ (Fig. $3 \mathrm{D})$. It can be expected that $\mathrm{Mcl}-1$ downregulation is the main candidate for TRAIL sensitization.

\section{Discussion}

Gastric cancer is one of the most common malignancies worldwide, particularly in east Asia. The prognosis remains poor despite significant progress in the treatment over the last decades. Despite the powerful activity of TRAIL towards most types of cancer cells, some tumors, including gastric cancer cells, display intrinsic or acquired resistance to TRAILinduced apoptosis. Avenues must be explored to overcome the resistance. In the present study, we found that TRAIL could stimulate apoptosis in the two gastric cancer cell lines, 
A

\begin{tabular}{llllllllllll} 
& \multicolumn{3}{c}{ BGC-823 } & & \multicolumn{3}{c}{ SGC-7901 } \\
\cline { 2 - 5 } \cline { 6 - 8 } TRAIL & - & + & - & + & & - & + & - & + \\
U0126 & - & - & - & + & + & & - & - & + & +
\end{tabular}

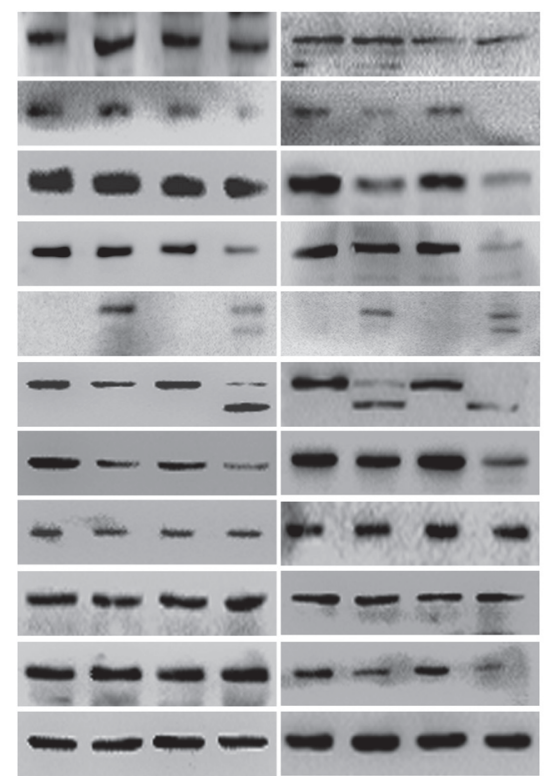

pro-caspase-8

Bid

pro-caspase-9

pro-caspase-3

cleaved-caspase-3

PARP

XIAP

Survivin

ClAP1

CIAP2

$\beta$-actin
C

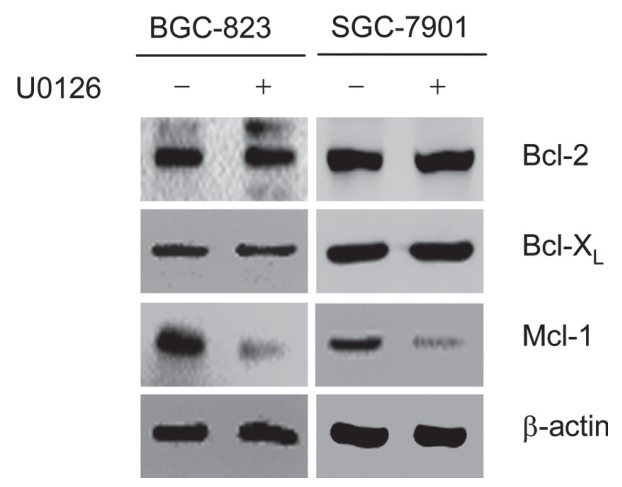

D

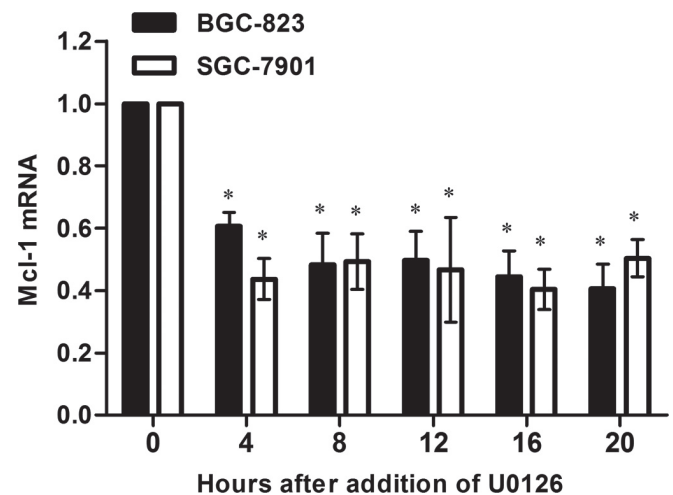

B

Untreated

TRAIL

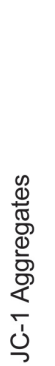

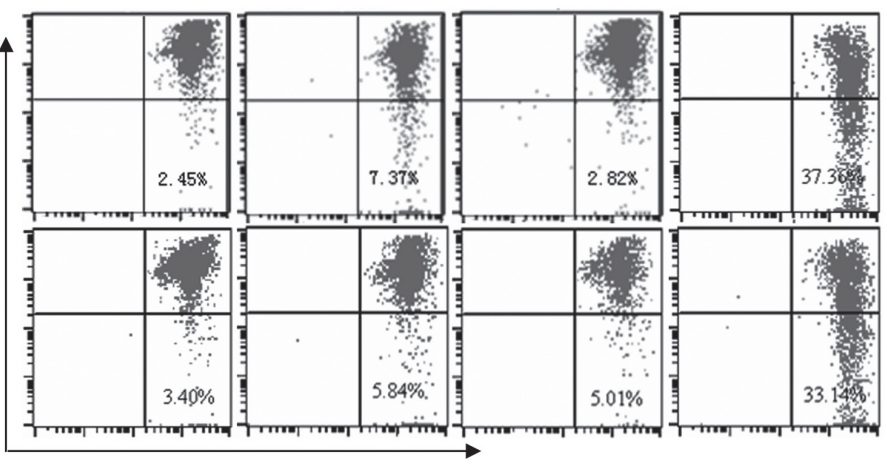

JC-1 Monomers
BGC-823

SGC-7901

Figure 3. MEK inhibition increases the activation of caspases, decreases MMP and downregulates the expression level of XIAP, cIAP2 and Mcl-1. Cells were treated with TRAIL for $3 \mathrm{~h}$, U0126 for $20 \mathrm{~h}$ or U0126 for $20 \mathrm{~h}$ followed by TRAIL for another $3 \mathrm{~h}$. A, Whole-cell lysates were subjected to Western blot analysis of pro-caspase-8, Bid, pro-caspase-9, caspase-3, PARP, XIAP, Survivin, cIAP1 and cIAP2 levels. $\beta$-actin was used as a internal control. $\mathrm{B}$, The MMP was measured by uptake of JC-1 using flow cytometry. The number in each lower-right quadrant represents the percentage of cells with reduction in MMP. C, Cells were treated with U0126 for $20 \mathrm{~h}$, then subjected to measurement of Mcl-1, Bcl-2 and Bcl-X expression by Western blot analysis. D, Cells were treated with U0126 for the indicated time points before measurement of Mcl-1 mRNA using real-time PCR. Results are expressed as mean \pm SD. ${ }^{*} \mathrm{p}<0.05$ vs $0 \mathrm{~h}$.

and its activity was mediated by activating both the extrinsic (caspase-8-mediated) and the intrinsic (caspase-9-mediated) pathways.

Extracellular signals are transduced into the cells via a complex network. Specificity of the cellular response is determined by an equilibrium which is reached between a host of distinct pathways. In recent years, several reports have demonstrated that TRAIL is able to activate NF- $\mathrm{BB}$, Akt, JNK and ERK1/2 pathways. These pathways may play roles in counteracting the apoptosis-inducing potential of TRAIL. When constitutively 
active, NF- $\mathrm{kB}$ and Akt confers TRAIL resistance, and blockage of these two pathways reverses the resistance to TRAIL [14, 16, 21-24]. The role of JNK activation in apoptosis is highly controversial, being suggested to have a pro-apoptotic (JNK1a2 and/or JNK1 $\beta 2$ ), anti-apoptotic (JNK1 $\alpha 1$ and/or JNK1 $\beta 1$ ) or no role in this process [25]. In hepatocellular carcinoma cells, inhibition of JNK also enhanced the sensitivity to TRAIL [26]. In squamous cell carcinoma cells, it is proposed that sustained activation of JNK initiates cell death, while transient activation of JNK favors cell survival [27].

Usually, the activation of ERK1/2 in response to death stimuli is believed to have an anti-apoptotic effect, based on the evidence of TRAIL-induced rapid ERK activation in certain tumor cell lines, and inhibition of ERK1/2 sensitizes TRAIL-resistant tumor cells to TRAIL [28-30]. In the present study, we focused on the effect of ERK1/2 pathway in TRAIL signaling.

TRAIL induced rapid but relatively transient phosphorylation of ERK1/2 in gastric cancer cells and inhibition of MEK, which is upstream of ERK1/2, by U0126, decreased ERK1/2 phosphorylation and reversed the resistance of cells to TRAIL-induced apoptosis. It is worthwhile to note that inhibition of MEK by itself did not induce apoptosis. This suggests that constitutively activation of ERK1/2 kinase is not needed for survival of the gastric cancer cells and only becomes important for survival when activated by exogenous stimuli, such as TRAIL. However, in diffuse large B-cell lymphoma, the novel MEK inhibitor, AZD6244, induced Bim-dependent apoptosis [31].

Combined treatment with U0126 and TRAIL resulted in marked cleavage of Bid, activation of caspase- 9 , loss of mitochondrial membrane potential, and enhanced activation of caspase- 3 and PARP cleavage. These findings indicate that both the extrinsic and intrinsic pathway were involved in the sensitization of U0126 to TRAIL-induced apoptosis.

Although the expression levels of Survivin and cIAP1 were not changed, notable decrease of XIAP occurred in the two cell lines. And in SGC-7901 cells, cIAP2 downregulation was also observed. It can be expected that downregulation of XIAP and cIAP2 may be an important factor for modulating TRAIL sensitivity.

At the level of mitochondria, anti-apoptotic Bcl-2 family proteins have been shown to protect cells against TRAILinduced apoptosis. Evidence is accumulating that Mcl-1 may play more profound roles than $\mathrm{Bcl}-2$ and $\mathrm{Bcl}-\mathrm{X}_{\mathrm{L}}$ in response to a variety of death stimuli. Mcl-1 binds and sequesters Bax and Bak blocking their ability to form pores in the mitochondrial membrane and to release cytochrome c into the cytoplasm. Degradation of Mcl-1 frees Bax and Bak allowing their polymerisation and activating apoptosis [32]. Enhanced Mcl-1 expression has been observed in multiple human cancers, often in association with poor prognosis, disease recurrence, or drug resistance [33-35]. In our study, Mcl-1 expression was elevated in the gastric cancer cells, while U0126 decreased its expression level. Reduction in Mcl-1 abundance is most frequently observed upon inhibition of the ERK1/2 pathway and this partly reflects direct ERK1/2-dependent regulation of Mcl-1 [36]. Inhibition of ERK1/2 promotes the proteasomedependent degradation of Mcl-1 whereas activation of ERK1/2 inhibits the degradation of Mcl-1. ERK1/2 phosphorylates Mcl-1 directly at $\mathrm{Thr}^{163}$ within the PEST domain and this stabilizes Mcl-1 [37].

Taken together, this report demonstrated that ERK1/2 activation provided the early-stage protection against TRAIL, and MEK inhibitor (U0126) could sensitize gastric cancer cells to TRAIL-induced apoptosis by promoting activation of the apoptotic pathway. Extensive preclinical data support the importance of the MAPKs signaling pathway in cancer biology and its potential as a therapeutic target in human cancers. Although many strategies have been developed to suppress MAPKs activity, small-molecule MEK inhibitors represent the most specific strategy tested to date. Combination of U0126 and TRAIL may achieve higher efficacy in a variety of tumors that are resistant to TRAIL.

Acknowledgments: This study was supported by the National Natural Science Foundation of China (No. 81071809), the Natural Science Research Project of Anhui Higher Education Institutions, China (No. KJ2011A167) and the Natural Science Research Project of Anhui Higher Education Institutions, China (No. KJ2012Z153).

\section{References}

[1] WILEY SR, SCHOOLEY K, SMOLAK PJ, DIN WS, HUANG $\mathrm{CP}$ et al. Identification and characterization of a new member of the TNF family that induces apoptosis. Immunity 1995; 3: 673-682. http://dx.doi.org/10.1016/1074-7613(95)90057-8

[2] NEWSOM-DAVIS T, PRIESKE S, WALCZAK H. Is TRAIL the holy grail of cancer therapy? Apoptosis 2009; 14: 607-623. http://dx.doi.org/10.1007/s10495-009-0321-2

[3] WALCZAK H, MILLER RE, ARIAIL K, GLINIAK B, GRIFFITH TS et al. Tumoricidal activity of tumor necrosis factor-related apoptosis-inducing ligand in vivo. Nat Med 1999; 5: 157-163. http://dx.doi.org/10.1038/5517

[4] HORAK P, PILS D, HALLER G, PRIBILL I, ROESSLER M et al. Contribution of epigenetic silencing of tumor necrosis factor-related apoptosis inducing ligand receptor 1 (DR4) to TRAIL resistance and ovarian cancer. Mol Cancer Res 2005; 3: 335-343. http://dx.doi.org/10.1158/1541-7786.MCR-04$\underline{0136}$

[5] BIN L, THORBURN J, THOMAS LR, CLARK PE, HUMPHREYS R et al. Tumor-derived mutations in the TRAIL receptor DR5 inhibit TRAIL signaling through the DR4 receptor by competing for ligand binding. J Biol Chem 2007; 282: 28189-28194. http://dx.doi.org/10.1074/jbc.M704210200

[6] YANG JK. FLIP as an anti-cancer therapeutic target. Yonsei Med J 2008; 49: 19-27. http://dx.doi.org/10.3349/ ymj.2008.49.1.19

[7] LEBLANC H, LAWRENCE D, VARFOLOMEEV E, TOTPAL $\mathrm{K}, \mathrm{MORLAN} J$ et al. Tumor-cell resistance to death receptorinduced apoptosis through mutational inactivation of the 
proapoptotic Bcl-2 homolog Bax. Nat Med 2002; 8: 274-281. http://dx.doi.org/10.1038/nm0302-274

[8] KANDASAMY K, SRINIVASULA SM, ALNEMRI ES, THOMPSON CB, KORSMEYER SJ et al. Involvement of proapoptotic molecules Bax and Bak in tumor necrosis factor-related apoptosis -inducing ligand (TRAIL)-induced mitochondrial disruption and apoptosis: differential regulation of cytochrome $\mathrm{c}$ and Smac/DIABLO release. Cancer Res 2003; 63: 1712-1721.

[9] FULDA S, MEYER E, DEBATIN KM. Inhibition of TRAILinduced apoptosis by Bcl-2 overexpression. Oncogene 2002; 21: 2283-2294. http://dx.doi.org/10.1038/sj.onc. 1205258

[10] BURNS TF, EL-DEIRY WS. Identification of inhibitors of TRAIL-induced death (ITIDs) in the TRAIL-sensitive colon carcinoma cell line SW480 using a genetic approach. J Biol Chem 2001; 276: 37879-37886.

[11] GILLISSEN B, WENDT J, RICHTER A, RICHTER A, MÜER A et al. Endogenous Bak inhibitors Mcl-1 and Bcl-xL: differential impact on TRAIL resistance in Bax-deficient carcinoma. J Cell Biol 2010; 188: 851-862. http://dx.doi.org/10.1083/ jcb.200912070

[12] TANIAI M, GRAMBIHLER A, HIGUCHI H, WERNEBURG $\mathrm{N}, \mathrm{BRONK}$ SF et al. Mcl-1 mediates tumor necrosis factor-related apoptosis-inducing ligand resistance in human cholangiocarcinoma cells. Cancer Res 2004; 64: 3517-3524. http://dx.doi.org/10.1158/0008-5472.CAN-03-2770

[13] CUMMINS JM, KOHLI M, RAGO C, KINZLER KW, VOGELSTEIN B et al. X-linked inhibitor of apoptosis protein (XIAP) is a nonredundant modulator of tumor necrosis factor-related apoptosis-inducing ligand (TRAIL)-mediated apoptosis in human cancer cells. Cancer Res 2004; 64: 3006-3008. http:// dx.doi.org/10.1158/0008-5472.CAN-04-0046

[14] KHANBOLOOKI S, NAWROCKI ST, ARUMUGAM T, ANDTBACKA R, PINO MS et al. Nuclear factor-kappaB maintains TRAIL resistance in human pancreatic cancer cells. Mol Cancer Ther 2006; 5: 2251-2260. http://dx.doi. org/10.1158/1535-7163.MCT-06-0075

[15] VILIMANOVICH U, BUMBASIREVIC V. TRAIL induces proliferation of human glioma cells by c-FLIPL-mediated activation of ERK1/2. Cell Mol Life Sci 2008; 65: 814-826. http://dx.doi.org/10.1007/s00018-008-7513-8

[16] LIU J, QU X, XU L, ZHANG Y, QU J et al. Phosphoinositide 3-kinase/Akt and nuclear factor $\mathrm{\kappa B}$ pathways are involved in tumor necrosis factor-related apoptosis-inducing ligand resistance in human gastric cancer cells. Mol Med Rep 2010; 3: 491-496. http://dx.doi.org/10.3892/mmr 00000286

[17] ROSKOSKI R JR. ERK1/2 MAP kinases: structure, function, and regulation. Pharmacol Res 2012; 66: 105-143. http:// dx.doi.org/10.1016/j.phrs.2012.04.005

[18] MCDAID HM, LOPEZ-BARCONS L, GROSSMAN A, LIA $M$, KELLER S et al. Enhancement of the therapeutic efficacy of taxol by the mitogen-activated protein kinase kinase inhibitor CI-1040 in nude mice bearing human heterotransplants. Cancer Res 2005; 65: 2854-2860. http://dx.doi.org/10.1158/ 0008-5472.CAN-04-4391

[19] ZHANG LJ, CHEN S, WU P, HU CS, THORNE RF et al. Inhibition of MEK blocks GRP78 up-regulation and en- hances apoptosis induced by ER stress in gastric cancer cells. Cancer Lett 2009; 274: 40-46. http://dx.doi.org/10.1016/ j.canlet.2008.08.030

[20] MIRMOHAMMADSADEGH A, MOTA R, GUSTRAU A, HASSAN M, NAMBIAR S et al. ERK1/2 is highly phosphorylated in melanoma metastases and protects melanoma cells from cisplatin-mediated apoptosis. J Invest Dermatol 2007; 127: 2207-2215. http://dx.doi.org/10.1038/sj.jid.5700870

[21] JANE EP, PREMKUMAR DR, POLLACK IF. Bortezomib sensitizes malignant human glioma cells to TRAIL, mediated by inhibition of the NF-\{kappa\}B signaling pathway. Mol Cancer Ther 2011; 10: 198-208. http://dx.doi.org/10.1158/1535-7163. MCT-10-0725

[22] AMMANN JU, HAAG C, KASPERCZYK H, DEBATIN KM, FULDA S. Sensitization of neuroblastoma cells for TRAIL-induced apoptosis by NF-kappaB inhibition. Int J Cancer 2009; 124: 1301-1311. http://dx.doi.org/10.1002/ijc.24068

[23] VACULOVA A, HOFMANOVA J, SOUCEK K, KOZUBIK A. Different modulation of TRAIL-induced apoptosis by inhibition of pro-survival pathways in TRAIL-sensitive and TRAIL-resistant colon cancer cells. FEBS Lett 2006; 580: 6565-6569. http://dx.doi.org/10.1016/j.febslet.2006.11.004

[24] TAZZARI PL, TABELLINI G, RICCI F, PAPA V, BORTUL $\mathrm{R}$ et al. Synergistic proapoptotic activity of recombinant TRAIL plus the Akt inhibitor Perifosine in acute myelogenous leukemia cells. Cancer Res 2008; 68: 9394-9403. http://dx.doi. org/10.1158/0008-5472.CAN-08-2815

[25] MAHALINGAM D, KEANE M, PIRIANOV G, MEHMET H, SAMALI A et al. Differential activation of JNK1 isoforms by TRAIL receptors modulate apoptosis of colon cancer cell lines. Br J Cancer 2009; 100: 1415-1424. http://dx.doi. org/10.1038/sj.bjc.6605021

[26] MUCHA SR, RIZZANI A, GERBES AL, CAMAJ P, THASLER WE et al. JNK inhibition sensitises hepatocellular carcinoma cells but not normal hepatocytes to the TNF-related apoptosis-inducing ligand. Gut 2009; 58: 688-698. http://dx.doi. org/10.1136/gut.2008.154625

[27] NOUTOMI T, ITOH M, TOYOTA H, TAKADA E, MIZUGUCHI J. Tumor necrosis factor-related apoptosis-inducing ligand induces apoptotic cell death through c-Jun NH2-terminal kinase activation in squamous cell carcinoma cells. Oncol Rep 2009; 22: 1169-1172.

[28] LEE TJ, LEE JT, PARK JW, KWON TK. Acquired TRAIL resistance in human breast cancer cells are caused by the sustained cFLIP(L) and XIAP protein levels and ERK activation. Biochem Biophys Res Commun 2006; 351: 1024-1030. http://dx.doi.org/10.1016/j.bbrc.2006.10.163

[29] ZHANG XD, BORROW JM, ZHANG XY, NGUYEN T, HERSEY P. Activation of ERK1/2 protects melanoma cells from TRAIL-induced apoptosis by inhibiting Smac/DIABLO release from mitochondria. Oncogene 2003; 22: 2869-2881. http://dx.doi.org/10.1038/sj.onc. 1206427

[30] LUNGHI P, GIULIANI N, MAZZERA L, LOMBARDI G, RICCA $\mathrm{M}$ et al. Targeting MEK/MAPK signal transduction module potentiates ATO-induced apoptosis in multiple myeloma cells through multiple signaling pathways. Blood 2008; 112 : 2450-2462. http://dx.doi.org/10.1182/blood-2007-10-114348 
[31] BHALLA S, EVENS AM, DAI B, PRACHAND S, GORDON LI et al. The novel anti-MEK small molecule AZD6244 induces BIM-dependent and AKT-independent apoptosis in diffuse large B-cell lymphoma. Blood 2011; 118: 1052-1061. http://dx.doi.org/10.1182/blood-2011-03-340109

[32] THOMAS LW, LAM C, EDWARDS SW. Mcl-1; the molecular regulation of protein function. FEBS Lett 2010; 584: 2981-2989. http://dx.doi.org/10.1016/j.febslet.2010.05.061

[33] SALERNI BL, BATES DJ, ALBERSHARDT TC, LOWREY $\mathrm{CH}$, EASTMAN A. Vinblastine induces acute, cell cycle phase-independent apoptosis in some leukemias and lymphomas and can induce acute apoptosis in others when Mcl-1 is suppressed. Mol Cancer Ther 2010; 9: 791-802. http://dx.doi. org/10.1158/1535-7163.MCT-10-0028

[34] CHETOUI N, SYLLA K, GAGNON-HOUDE JV, ALCAIDELORIDAN C, CHARRON D et al. Down-regulation of mcl-1 by small interfering RNA sensitizes resistant melanoma cells to fas-mediated apoptosis. Mol Cancer Res 2008; 6: 42-52. http://dx.doi.org/10.1158/1541-7786.MCR-07-0080

[35] MARTIN-PEREZ R, NIWA M, LOPEZ-RIVAS A. ER stress sensitizes cells to TRAIL through down-regulation of FLIP and Mcl-1 and PERK-dependent up-regulation of TRAIL-R2. Apoptosis 2012; 17: 349-363. http://dx.doi.org/10.1007/ s10495-011-0673-2

[36] BALMANNO K, COOK SJ. Tumour cell survival signalling by the ERK1/2 pathway. Cell Death Differ 2009; 16: 368-377. http://dx.doi.org/10.1038/cdd.2008.148

[37] DOMINA AM, VRANA JA, GREGORY MA, HANN SR, CRAIG RW. MCL1 is phosphorylated in the PEST region and stabilized upon ERK activation in viable cells, and at additional sites with cytotoxic okadaic acid or taxol. Oncogene 2004; 23: 5301-5315. http://dx.doi.org/10.1038/sj.onc.1207692 